\title{
EDUCATION
}

\section{A randomised controlled trial of the effect of outreach placement on treatment planning by dental students}

\author{
M. Smith, ${ }^{1}$ M. A. Lennon, ${ }^{2}$ A. H. Brook, ${ }_{1}^{3}$ F. A. Blinkhorn, ${ }_{1}^{4}$ A. S. Blinkhorn ${ }^{5}$ and P. G. Robinson ${ }^{6}$
}

"...there is a widespread belief that outreach placements can broaden the base of available clinical material and enhance the educational experience."

\footnotetext{
${ }^{1 *}$ Outreach Programme Evaluator, ${ }^{2}$ Outreach Programme Manager, ${ }^{3}$ Dean of the Faculty of Medicine, Department of Oral Health and Development, School of Clinical Dentistry, University of Sheffield, Claremont Crescent, Sheffield S10 2TA; ${ }^{4}$ Clinical Director of Dental Services, Lance Burn Health Centre Churchill Way, Salford, Manchester, M6 5AU; ${ }^{5}$ Professor of Oral Health, School of Dentistry, The University of Manchester, Higher Cambridge Street, Manchester, M15 6FH; ${ }^{6}$ Professor of Dental Public Health Department of Oral Health and Development, School of Clinical Dentistry, University of Sheffield, Claremont Crescent Sheffield, S10 2TA

${ }^{*}$ Correspondence to: Mr Michael Smith

Email: michael.smith@sheffield. ac.uk
}

Undergraduate dental students' curricula are being supplemented with primary care placements.

Objective To compare the effect of outreach placement and traditional hospital-based training alone on students' treatment planning ability

Design Randomised controlled trial.

Setting Four existing primary care placements in England during 2004.

Subjects and methods At follow-up the fourth-year students took a history from a standard 'patient' then recorded a treatment plan. Interview skill was scored. The history and plan were assessed by clinicians blind to the intervention. Intervention Five-week block outreach placements for 25 of 49 students.

Main outcome measures Interviewing skill, quality of dental and social histories, the appropriateness of planned treatments and the consideration of wider issues.

Results The two groups were similar in the scores for interviewing and taking a dental history. The outreach group scored higher for capturing a social history (outreach mean 4.4, SD $=2.1, n=22$ and hospital 2.8, $S D=1.9, n=23 ; p$ $=0.01)$ and for developing an appropriate treatment plan (5.6 $[S D=2.1]$ and $3.9[S D=2.3] ; p=0.01)$. There were no differences in scores relating to the wider issues.

Conclusion Dental outreach training was significantly more effective than traditional training alone in improving students' ability to capture relevant points of social history from a patient and to consider them when planning treatment.

\section{INTRODUCTION}

Many dental schools are increasing the role of primary care placements in new curricula to enhance students' learning ${ }^{1}$ and prepare them to meet communities' needs. ${ }^{2}$ Such placements complement students' traditional hospital-based training and are variously termed outreach, extramural or community-based placements. Most students will later work in primary care settings.

Surveys of outreach programmes encourage their development ${ }^{3,4}$ and there is a widespread belief that such placements can broaden the base of available clinical material and enhance the educational experience. ${ }^{1}$ This view is supported by many positive programme evaluations ${ }^{5-8}$ and the occasional cautionary one. ${ }^{9}$ There is limited evidence on the impact of outreach programmes and a call for further research. ${ }^{3}$

The University of Sheffield's School of Clinical Dentistry is developing an undergraduate outreach programme. The first phase saw returning students claiming increased understanding of pragmatic treatment planning with increased appreciation of patients' social circumstances. ${ }^{10}$ These skills and understanding are essential components in dental curricula ${ }^{1,11,12}$ and similar observations have been made in other uncontrolled programme evaluations. ${ }^{13,14}$

The aim of this randomised controlled trial was to compare the effectiveness of dental outreach in a primary dental care setting and a traditional, hospitalbased training in increasing the competence of dental students to plan treatment for patients with common dental problems.

The construct of treatment planning underpinning this study has three stages:

- Interviewing

- Identifying relevant information in dental and social histories, and

- Using that information to formulate a treatment plan.

The first stage and the associated capture of a dental history are familiar and well practiced tasks for senior dental students. Consequently, we hypothesised that outreach experiences would not improve performance in these respects. The remaining stages, collecting relevant information from the social history and using that information to plan appropriate treatment, were hypothesised to benefit. 


\section{MATERIALS AND METHODS}

The intended sample was all 54 fourth year, senior students at the University of Sheffield's School of Clinical Dentistry. Excluded from the sample were any students who declined to participate or who attended overseas dental schools during the semester.

Student representatives were involved in the experiment's design, which was then presented to the whole cohort before recruitment. Students were reassured throughout that participation decisions and allocations would not adversely affect their studies. The study gained ethical approval from the North Sheffield Research Ethics Committee in March 2004 and the protocol was followed throughout.

\section{Allocation}

Students in three timetable blocks were randomised into the hospital or outreach placements using electronically generated random numbers. Allocations were concealed from students until baseline assessments were completed.

\section{Intervention}

The outreach group attended National Health Service (NHS) salaried primary dental care placements full time for five weeks. Eighteen placements were in two Dental Access Centres (DACs provide care including emergency care for people experiencing difficulty in accessing NHS dental care) and seven in two Community Dental Services (the CDS provides community-based specialist services such as oral health promotion and caters for children in otherwise underserved areas and patients with special dental needs) in locations in urban areas of identified need. Each week students had between five and seven half-day clinical sessions with dental nurse support, working to local protocols and supervised by local dentists. In addition they observed other local healthcare services and completed a written project relating two patients' case studies to community public health data. ${ }^{15}$

The outreach group attended the placements consecutively throughout the 2004 summer term. The hospital group continued their normal dental hospital clinics including restorative and casualty clinics for the five weeks while the outreach blocks were on placement.

\section{Baseline measures}

Students' clinical competence was established through two pragmatically selected measures to check randomisation. Self-assessed competence was measured using a five-point Likert scale ranging from poor to excellent and scored 1, poor, to 5, excellent, to the question "Your training aims to help you plan treatment for patients taking into consideration the clinical states of their mouths and relevant factors in their everyday lives. How good do you think you are at treatment planning?" Competence of the student was also assessed using average formative marks in dental hospital clinical assessments throughout the previous semester.

\section{Follow up assessments}

Follow up assessments considered interviewing skills, capture of social history and treatment planning. Interviewing skills were assessed practically with a standardised patient. Performance in the remaining two stages was by written report and oral assessment. The assessments were held the day after each placement ended and students were aware of the assessments being made.

Measures of the type used at follow-up were not conducted at baseline in case repeated assessments might prime the students.

\section{The trial}

The 'patient' was selected from a bank of actors, who simulate patients, to match the history: a disadvantaged young mother presenting with poor oral health, several decayed teeth and severe pain (see Fig.1).

The patient is a 25 year old mother and single-parent to children aged seven and three, with no other family living in the same city. The family live in disadvantaged circumstances in an apartment in an area of social housing served by a few small shops and an infrequent bus service. Their home is three miles (five kilometres) from the surgery and as they do not have access to a car the journey entails a change of buses.

The family diet of convenience foods and sweet drinks is evident from the shopping in her bag. The mother is a moderate smoker and drinks about seven units of alcohol a week. Unemployed, she has poor educational attainment.

The elder child has poor oral health and rarely cleans his teeth. Neither child visits the dentist.

The mother has no history of regular dental treatment and poor attendance for appointments. She wants such things 'over and done with' even if that requires the extraction of posterior teeth. She has many severely decayed teeth. This visit to the dentist is prompted by persistent severe pain in the upper left quadrant.

Fig. 1 The history portrayed by the standardised patient

Students were instructed to take a complete history of the 'patient' and formulate a treatment plan on a standardised clinical recording sheet but without examining the patient-actor's mouth. They were then introduced to the patient and left alone for 10 minutes. Students interviewed the 'patient' in a surgery with her completed dental chart, orthopantomograph and standard self-completion medical history form. The patient's shopping bag on the floor contained convenience foods and soft drinks. Afterwards the student had five minutes alone to prepare and record the history and treatment plan before being assessed for 10 minutes by two clinicians experienced in children's and community dentistry (ASB, FAB).

Students were asked not to discuss the case with their peers and the assessment timetable reduced the opportunities for contact between students.

Assessment of the interview by the 'patient' used the Arizona Clinical Interview Rating (ACIR), a construct validated 16 -item scale measuring interviewing skill ${ }^{16}$ with good discriminative validity and responsiveness 
Dental history captured

- Diet of the patient

- Attendance pattern of the patient

- Oral hygiene of the patient

\section{Social history captured}

- Patient's access - transport problems

- Patient's access - childcare problems

Treatment plan

- An appropriate solution for pain relief

o A plan for repeated patient visits that is cognisant

of social factors including:

- Unlikely to attend for many visits

- Patient's wishes

- A plan for prevention of dental disease for the patient that is cognisant of her social factors

Wider issues within the plan

- Identifying if her children have unmet dental treatment/preventive needs

- A multi-disciplinary approach to health promotion in this family

Codes 0-3 were applied to each of the eleven items marked $\bullet$.

The items were coded 0 if not present in the written or oral report, 1 if hesitantly present only on prompt, 2 if readily present on prompt or 3 if spontaneously present.

Fig. 2 Grading the oral assessment

in evaluating dental curricular developments. ${ }^{17,18}$ This 'patient' assessment was supplemented by subsequent second rating by an experienced clinician (FAB) via unobtrusive, but visible, audio recording of the interviews. Second ratings omitted the two non-verbal communication scale items.

Students' record sheets were independently read by the two clinicians (ASB, FAB). The written histories and treatment plans were awarded provisional codes 0 , absent, to 3, spontaneously present, for items listed in Figure 2. An agenda was then agreed for questioning the student to clarify any areas of uncertainty. After 10 minutes questioning the assessors independently revised and recorded their assessment codes before discussing any differences and agreeing a joint assessment. The histories and treatment plans were scored as the sums of codes in each of the four areas.

The development of these assessments occupied four days. After initial training to portray her role consistently the patient was trained and calibrated as an ACIR assessor by first rating experienced clinicians and then other dental students. Later, adjustments were made to the patient description (Fig. 1), the simulation and the assessment criteria and codes (Fig. 2) during refine- ment and calibration ${ }^{17,19}$ with other students until the assessors were confident the assessment was valid and reliable.

To reduce reactive effects, all assessments and administration were conducted by staff not involved with the students' course and student anonymity was maintained. To increase the assessment's validity, follow up data were collected in a simulated general practice in a dental school annex with students wearing clinical uniform.

Follow up assessment was blind to group assignment and carried out by staff from a different dental school. The effectiveness of this blinding was evaluated by the assessors' stating their perception of the probable allocation at the end of each interview. One assessor could not predict 37 of 45 students' allocations, identified 7 correctly and 1 incorrectly. The other assessor could not predict 24, identified 11 correctly and 10 incorrectly. Blinding of the assessors to the intervention was therefore deemed to be effective.

After describing all variables for the two groups and making simple comparisons of potential confounders, statistical analysis by t test was used to compare the outcome measures between the groups. Data were also compared between groups using analysis of covariance and checks made of the effects of likely potential confounding and mediating factors using multiple regression analyses. Those potential confounding factors, identified in findings from earlier studies, were the placement setting, number of student co-workers, number of years of teaching experience of placement supervisors, number of visits to other healthcare activities and student attendance.

Finally, intention to treat analyses (substituting data for those lost to follow-up) of group comparisons were made for the outcome variables using two imputations for missing data. The first used substitution of the sample mean ${ }^{20}$ and the second with the sample mean plus one standard deviation for the control group and the mean minus one standard deviation for the outreach group. ${ }^{21}$

\section{RESULTS}

All 49 eligible students consented to participate. Fourteen of the 25 students in the outreach group were female as were 15 of the 24 in the hospital group. The groups were similar at baseline for both measures of clinical competence (Table 1).

Following recruitment and baseline data gathering in March 2004, students started their allocated experiences in April, May or June and returned for follow

Table 1 Baseline measures

\begin{tabular}{|l|l|l|}
\hline & $\begin{array}{l}\text { Outreach } \\
n=25 \\
\text { mean }\end{array}$ & $\begin{array}{l}\text { Hospital } \\
n=24 \\
\text { mean }\end{array} \quad$ (SD)
\end{tabular}


"...outreach

training

was more

effective than

traditional

hospital-based

training alone

in improving

students'

ability to

capture

relevant points

of social

history from a

patient and to consider these when planning treatment."

Table 2 Follow up measures

\begin{tabular}{|c|c|c|c|c|}
\hline & $\begin{array}{l}\text { Out } \\
\mathrm{n}= \\
\text { mea }\end{array}$ & $(S D)$ & $\begin{array}{l}\text { Hospital } \\
n=23 \\
\text { mean }\end{array}$ & (SD) \\
\hline \multicolumn{5}{|l|}{ Stage 1 - Interviewing skill } \\
\hline Patient's rating & 62 & (4) & 63 & (5) \\
\hline Dentist's rating & 40 & (12) & 40 & (8) \\
\hline \multicolumn{5}{|l|}{ Stage 2 - Information capture } \\
\hline Dental history obtained & 5.0 & $(3.5)$ & 4.8 & (3.0) \\
\hline Social history obtained & 4.4 & $(2.1)^{* *}$ & 2.8 & $(1.9)^{* *}$ \\
\hline \multicolumn{5}{|l|}{ Stage 3 - Treatment planned } \\
\hline Treatment planning was appropriate & 5.6 & $(2.1)^{* *}$ & 3.9 & $(2.3)^{* *}$ \\
\hline Inclusion of wider issues & 2.6 & $(1.7)$ & 2.3 & $(1.4)$ \\
\hline
\end{tabular}

up assessment five weeks later. One student failed to complete the allocated experience through illness. A further three students were unable to attend the assessment due to personal commitments or illness. So 22 of 25 outreach students and 23 of 24 in the hospital group provided data for analysis.

At follow up interviewing skills, as measured using the ACIR, were similar in the outreach and hospital groups whether assessed by the patient or the dentist (Table 2). Further, the patient's and dentist's scores showed moderate correlation (Pearson $r$ 0.49, p <0.01, $\mathrm{n}=45$ ). Distributional requirements for parametric analysis were met for all measures.

The scores for capture of a dental history were similar in both groups. However, the outreach group's score for the capture of the social history was higher than the hospital group's (4.4 cf 2.8, p = 0.01).

The outreach group scored significantly higher for first part of appropriate treatment planning (5.6 cf 3.9, $p=0.01$ ) but not for the inclusion of wider issues.

The ancillary analyses revealed no significant variation in scores by date of attendance, student gender or any of the factors identified in earlier studies and listed above with the exception of placement setting. One way ANOVA of the primary outcomes by placement setting for the outreach group indicates that CDS experiences were more influential than DAC ones in capturing a dental history and including the wider issues in treatment planning.

Intention to treat analyses for the capture of social history gave $\mathrm{p}=0.01, \mathrm{n}=49$, using the sample mean as a substitute value. The more parsimonious imputation using one standard deviation above mean for the outreach group and one standard deviation below for the hospital group gave a $p$ value of 0.07 . The corresponding values for appropriate treatment planning were $\mathrm{p}=0.01$ and 0.09 .

\section{DISCUSSION}

This randomised controlled trial found outreach training more effective than traditional hospital-based training alone in improving students' ability to capture relevant points of social history from a patient and to consider these when planning treatment.

Our hypotheses that outreach experiences would not improve competence in the familiar tasks of interviewing and taking a dental history but would have a beneficial effect on capturing a social history and planning appropriate treatment were supported.

Our findings provide robust support for the widespread belief in the value of placements and in policy makers' recommendations to use outreach in primary care to develop 'professionals who are best suited to providing appropriate... care ${ }^{22}$ through heightening students' awareness of community needs.

DeCastro et al. in a recent US study ${ }^{23}$ finding that outreach students graduated with higher examination board score suggested this improvement may be due to increased clinical experiences. This is also a plausible explanation in our study, though perhaps the favourable supervision ratio, nursing support and the location of the learning in a working environment are other relevant factors.

While the study does identify educational gains from outreach placements there are associated educational costs. For example, there may also be lost opportunity costs to students' learning in other fields resulting from these being away from the dental school and research into this may be valuable. There is also a need for further research into the specific educational benefits arising from different types of primary care settings as suggested by the exploratory analysis.

The outreach experience in this study involved working three or more days a week as a member of a primary care team separate from the dental school and 
hospital, and completing a community public health project. Students were supervised by local staff and had experienced, individual dental nursing support. There may be limitations on generalising the findings to other schemes operating in different ways or in contexts where producing graduates prepared to address social issues is not a high priority. However, other features of the trial increase the external validity of this study: the patient's case was unexceptional, the skills assessed were everyday requirements of many dentists, the assessment setting was a typical surgery, four independent outreach locations were used, students were not selected to participate, and blinding of the assessors to the intervention was successful. Further, the measure of treatment planning achieved construct validity and reliability through thorough development and practice. A factor in ensuring this validity was assessment by clinician assessors familiar with the NHS primary care sector that engages most of the dental workforce. While other treatment plans might be argued, the assessments rewarded approaches that acknowledged the patients' condition, preferences and circumstances.

The benefits of outreach experience did not extend to the more frequent inclusion in treatment plans of the wider issues of the patient's children's needs or multidisciplinary health promotion. It may be that while five weeks outreach experience had helped students move to a more holistic consideration of the patient's needs, this improvement had neither extended to consideration of the family as a whole nor to matters which were not predominantly dental in nature. Alternatively, the students may have deemed these issues of secondary importance whilst considering a patient experiencing severe pain.

Debate remains regarding different approaches to intention to treat analysis. ${ }^{20,24}$ What is clear is that a loss to follow up which is less than $10 \%$ and which is random has little effect on comparisons. ${ }^{20}$ This was confirmed by substitution with sample means and only challenged when the imputations assumed a worst case outcome for missing data.

\section{CONCLUSION}

This trial found outreach experiences as an adjunct to traditional hospital-based training were effective in improving students' ability to capture a patient's social history and to plan appropriate treatment in the light of that social history. These findings support further development of outreach in dental education as a contribution to achieving community public health objectives. ?

The authors wish to acknowledge the support of placements staff and patients in providing suitable learning opportunities for students, Jackie Shaw's contribution in developing the patient's role, Hilary Broder's advice regarding simulated patients and the students for their cooperation. This study was supported by NDDU grants EL1/EL2.
1. General Dental Council. The first five years: a framework for undergraduate dental education. 2nd ed. pp 13. London: GDC, 2002.

2. Andersen R M, Davidson P L, Atchison K A et al. Pipeline, profession and practice programme: evaluating change in dental education. J Dent Educ 2005; 69: 239-248.

3. Bailit H. Community-based clinical education programs. Major findings and recommendations. J Dent Educ 1999; 63: 981-989.

4. Hogan H. Preparing for practice: an analysis of the state of community-based medical education in the US. Nuffield Trust Travelling Fellowship Reports Series No.1. pp 109-116. London: The Nuffield Trust for Research and Policy Studies in the Health Services, 1999.

5. Pau A K H, Croucher R. A dental practice placement scheme: benefits for practitioners and undergraduates. Eur J Dent Educ 2001; 5: 155-161.

6. Skelton J, Mullins M R, Kaplan A L, West K P, Smith T A. University of Kentucky community-based field experience: program description. J Dent Educ 2001; 65: 1238-1242.

7. Lennon M A, Ireland R S, Tappin J et al. The personal dental service as a setting for an undergraduate clinical programme. Br Dent J 2004; 196: 419-422.

8. Woronuk J I, Pinchbeck Y J, Walter M H. University of Alberta dental students' outreach clinical experience: an evaluation of the program. J Can Dent Assoc 2004; 70: 233-236.

9. Miller $S \mathrm{~L}$, Heil J. Effect of an extramural program of dental care for the special patient on attitudes of students. J Dent Educ 1976; 40: $740-744$

10. Smith M, Lennon M A, Brook A H, Ritucci L, Robinson P G. Student perspectives on their recent dental outreach placement experiences. Eur J Dent Educ 2006; 10: 80-86.

11. Commission on Dental Accreditation. Accreditation standards for dental education programs. pp 5-7, 15. Chicago: CDA, 2001.

12. Plasschaert A J M, Holbrook W P, Delap E, Martinez C, Walmsley A D. Profile and competences for the european dentist. Association for Dental Education in Europe. Eur J Dent Educ 2005; 9: 98-107.

13. Elkind A, Blinkhorn A S, Blinkhorn F A et al. Developing dental education in primary care: the student perspective. Br Dent J 2005; 198: 233-237

14. DeCastro J E, Matheson P B, Panagakos F S, Stewart D C, Feldman C A. Alumni perspectives on community-based and traditional curricula. J Dent Educ 2003; 67: 418-426.

15. Harris R V, Dailey Y, Lennon M A. Recording and understanding social histories by dental undergraduates in a community-based clinical programme. Eur J Dent Educ 2003; 7: 34-40.

16. Stillman P L, Brown D R, Redfield D L, Sabers D L. Construct validation of the Arizona clinical interview rating scale. Educ Psychol Meas 1977; 37: 1031-1038.

17. Broder H L, Felman C A, Saporito R A, Stilwell N S. Implementing and evaluating a patient instructor program. J Dent Educ 1996; 60: 755-762.

18. Pfeiffer $C$, Madray M, Ardolino A, Willms J. The rise and fall of students' skill in obtaining a medical history. Med Educ 1998; 32: 283-288.

19. Barrows H S. An overview of the uses of standardized patients for teaching and evaluating clinical skills. Acad Med 1993; 68: 443453.

20. Wright C C, Sim J. Intention-to-treat approach to data from randomized controlled trials: a sensitivity analysis. J Clin Epidemiol 2003; 56: 833-842.

21. Sackett D L, Richardson W S, Rosenberg W M C, Haynes R B. Evidence-based medicine: how to practice and teach EBM. 2nd ed. pp 109. London: Churchill Livingstone, 2000.

22. Department of Health. NHS dentistry: options for change. pp 50 London: Department of Health, 2002.

23. DeCastro J E, Bolger D, Feldman C A. Clinical competence of graduates of community-based and traditional curricula. J Dent Educ 2005; 69:1324-1331.

24. Higgins J P T, Green S (eds). Cochrane handbook for systematic reviews of interventions 4.2 .5 section 8.4. In The Cochrane library. Issue 3. Chichester: John Wiley \& Sons. 